\title{
On the austerity policies in the Eurozone: What can we learn after the crisis?
}

\author{
José Luis Parada-Rodríguez* j.parada@ufv.es \\ Universidad Francisco de Vitoria \\ Nieves Carmona-González* n.carmona@ufv.es \\ Universidad Francisco de Vitoria \\ Carmen Díaz-Roldán**_ carmen.diazroldan@uclm.es \\ Universidad de Castilla-La Mancha \\ and Instituto de Economía Internacional
}

\begin{abstract}
In the Eurozone, the financial crisis effects have been hit countries in a different manner. Austerity policies have not been good for everyone and have caused inequality in some groups. Some countries of the periphery have showed more vulnerable, producing alarming figures on output decreases and unemployment increases, particularly those of young unemployment. This compromise the inter-generational aspects of sustainable growth and development.

In this paper, we consider an economic framework featuring the use of monetary and fiscal rules within a monetary union. In this scenario, that should be representative of the Eurozone, we will analyse the effects of stabilization policies when dealing with a financial crisis having contractive effects on output.

Using data provided by Eurostat, we will perform an empirical application for three sets of European countries: the core, the peripheral, and the Eastern countries. In our analysis, we will also differentiate countries according with their historical unemployment path. We will show the results of stabilization fiscal policies by the supply-side, in terms of output and young unemployment before the crisis, 2007, and ten years later, 2017. The exercises will be performed under different degrees of conservativeness of the central bank, austerity of the fiscal authorities and different levels of public debt. Our results could help us to stablish the conditions under which stabilization policies have would lead to a less inequality outcomes.
\end{abstract}

Key words: Monetary unions, fiscal consolidation, youth unemployment, inequality. JEL Codes: E62, E63, H6

\footnotetext{
* Universidad Francisco de Vitoria. Facultad de Ciencias Jurídicas y Empresariales. Carretera Pozuelo a Majadahonda, Km 1.800, 28223 Pozuelo de Alarcón, Madrid (Spain)

** Universidad de Castilla-La Mancha. Facultad de Derecho y Ciencias Sociales. Ronda de Toledo s/n. 13071 Ciudad Real (Spain)
} 


\section{Introduction}

In the Eurozone, the financial crisis effects have been hit countries in a different manner. Certain groups of the periphery have showed more vulnerable, producing alarming figures on output decreases and unemployment increases, particularly those of youth unemployment. This compromise the inter-generational aspects of sustainable growth and development. The process of job destruction, which began after the crisis initiated in 2007, has had a particularly negative effect on youth unemployment. This was already a structural problem in several countries, mainly developing and peripheral ones, which has been aggravated by the crisis. Youth unemployment, by affecting the economic situation of the younger population, compromises the potential growth and the sustainability of the economy.

These problems become particularly relevant in the case of the member countries of a monetary union facing a sovereign debt crisis, given that fiscal policy is the only domestic stabilization policy, and is also constrained by the need to carry out fiscal consolidation and reduce debt levels. But even in a set of integrated economies as the European Union (EU) and the Eurozone prove to be, the policies measures adopted for recovering after the crisis become of special relevance. For contributing to the recovery of the recent crisis, based on the Juncker Plan, the European Fund for Strategic Investments (EFSI) is aimed to promote jobs and sustainable development (European Commission, 2017).

As was addressed by Blanchard (2004), the evolution of the average European unemployment rate hides large cross-country differences and the path of unemployment have been very different across countries. One of the reasons is that in the European Monetary Union (EMU), the member countries are characterized by the diversity of their labour markets. And given that labour market institutions differ across European countries, macroeconomic shocks, institutional changes, and international integration influence unemployment changes (Bertola, 2017). During the last decade, the Great Recession has had a profound impact. In 2017, youth unemployment (less than 25 years) in Germany, at $6.70 \%$, was the lowest of the Eurozone countries (18.33\% in average), followed by the Netherlands at $8.87 \%$. By contrast, the highest figures have been reached by Greece, $43 \%$, and Spain, 38\% (Eurostat).

In this paper, we will analyse, in strategic terms, the effects of stabilization policies on unemployment, using government deficit besides the use of fiscal policies by the supply side (FPSS). After calculating changes on unemployment figures, our results will characterize the economic framework conditions under which FPSS could reduce unemployment.

To that aim, we will made use of a simple model for a monetary union (DíazRoldán, 2017) using explicit policy rules and allowing for a more, or less conservative governor of the central bank. We will also consider both an austere and no austere fiscal policy and, finally, we will take in account the initial level of public debt of the member countries of the union. Our analysis will focus on the collective affected by youth unemployment, since compromise the inter-generational aspects of sustainable growth and development. 
In order to highlight the effects of the different macroeconomic performance among EMU members, in this paper, we will perform an empirical application for three sets of European countries: the core, the peripheral, and the Eastern countries. We will show the results of stabilization fiscal policies by the supply-side, in terms of output and young unemployment before the crisis, 2007, and ten years later, 2017.

The paper structures as follows: the next section is dedicated to show the modelling strategy, next we will perform an empirical application discussing the results. Finally, in the concluding remarks we will summarize the main findings and their policy implications.

\section{Modelling strategy}

\subsection{The baseline model}

We follow the approach by Díaz-Roldán (2017), in which a simple macroeconomic model describing a monetary union is developed. The common monetary authority tries to control inflation, while the national fiscal authorities are concerned by output stabilization; being they also constrained by the fiscal discipline imposed by monetary agreements. In such environment, we will try to explore which would be the optimal fiscal policies and their implications on macroeconomic variables when unions exert their bargaining power. To that aim, we will consider different preferences of the fiscal authorities, the possibility of conducting fiscal policies in an individual or in a coordinated way, as well as the scope of collective bargaining for stabilizing unemployment, after suffering a contractive demand shock, trying to describe the recent economic crisis shock. One of our contributions would be to include explicit monetary and fiscal rules. Finally, we will illustrate the theoretical results by performing an empirical exercise.

When performing our exercise, we will adopt the following assumptions: our model describes a small monetary union, formed by two countries. The Central Bank (CB) follows a monetary policy rule. We assume a conservative central banker, to characterize a monetary authority particularly concerned on inflation targeting goal. Regarding fiscal authorities they use a "disciplined" fiscal rule, i.e., the fiscal authority is more concerned on fiscal consolidation, reducing government deficit, than in promoting output growth. The fiscal authorities could reveal different preferences on fiscal austerity, i.e., giving more or less weight to government deficit deviations in their loss function, respect to output stabilization. The initial level of government debt could be also low or high. In this environment, the fiscal authorities can act in an individual (Nash solution) or in a coordinated manner (Cooperative solution), when deciding the level of government deficit.

In this scenario, for characterizing the role played by unions, we will assume that they could have or not bargaining power. When the bargaining power is positive, we find an active union trying to reduce unemployment even at the cost of reducing wages. If the union has no bargaining power, we would find the level of unemployment given by the market solution. 
Variables are defined as logarithmic deviations from their equilibrium levels. A more detailed description of the model can be found in the Appendix.

The aggregate demand and the aggregate supply functions for each country are as follows:

$$
\begin{aligned}
& y_{1}=-a \Delta p_{1} \pm b \Delta p_{2} \pm c y_{2}+h g_{1}+v_{1} \\
& y_{2}=-a \Delta p_{2} \pm b \Delta p_{1} \pm c y_{1}+h g_{2}+v_{2} \\
& y_{1}=t \Delta p_{1}-s_{1} \\
& y_{2}=t \Delta p_{2}-s_{2}
\end{aligned}
$$

Equations (1) and (2) represent the aggregate demand function for each member country of the monetary union, where $y_{1}, y_{2}$ are the outputs, $\Delta p_{1}, \Delta p_{2}$, the inflation rates, $g_{1}, g_{2}$ the budget deficits, i.e., the fiscal policy instrument, and $v_{1}, v_{2}$ capture any kind of expansionary demand shock. Equations (3) and (4) represent the aggregate supply function for each member country of the monetary union, where $s_{1}, s_{2}$ capture any expansionary supply side shock.

Solving (1) to (4), we obtain the reduced forms. Looking at the coefficients of the equations of the model (see Appendix), when monetary authorities are particularly concerned by inflation targeting and follow a monetary policy rule the "beggar-thyneighbour" effect prevails (demand shocks are transmitted abroad in an asymmetric way, i.e., with the opposite sign). Given that we will focus on the scope of fiscal policies when unions have bargaining power, aimed to deal with a demand shock for characterizing the recent crisis, we will neglect supply side shocks hereafter.

$$
\begin{aligned}
& y_{1}=\mathrm{A} h g_{1}+\mathrm{A} v_{1}-\mathrm{B} h g_{2}-\mathrm{B} v_{2} \\
& y_{2}=\mathrm{A} h g_{2}+\mathrm{A} v_{2}-\mathrm{B} h g_{1}-\mathrm{B} v_{1} \\
& \Delta p_{1}=\mathrm{A}^{\prime} h g_{1}+\mathrm{A}^{\prime} v_{1}+\mathrm{B}^{\prime} h g_{2}+\mathrm{B}^{\prime} v_{2} \\
& \Delta p_{2}=\mathrm{A}^{\prime} h g_{2}+\mathrm{A}^{\prime} v_{2}+\mathrm{B}^{\prime} h g_{1}+\mathrm{B}^{\prime} v_{1}
\end{aligned}
$$

Besides this consideration, we will also include in our model the restriction imposed by the requirement of achieving the fiscal discipline goal. To do that, we will allow the adoption of an explicit fiscal rule to characterize the deficit path followed by fiscal authorities. Following Ballabriga and Martínez-Mongay (2003), we will consider a fiscal rule which relates an explicit public deficit target (in terms of the GDP), $g^{o}$, with public debt deviations (in terms of the GDP) with respect to its optimal level $\left(d_{-1}-d^{o}\right)$, and the output level $y$ :

$$
g_{i}^{o}=-\left[\delta\left(d_{i,-1}-d_{i}^{o}\right)+\theta y_{i}\right] \quad i=1,2
$$

The public deficit adjusts according to the following path, where $0 \leq \rho \leq 1$ :

$$
g_{i}=(1-\rho) g_{i}^{o}+\rho g_{i,-1}
$$

From (9) and (10), we obtain the fiscal rules for each member country of the union:

$$
g_{i}=-(1-\rho) \delta\left(d_{i,-1}-d_{i}^{o}\right)+\rho g_{i,-1}-(1-\rho) \theta y_{i}
$$


Adding the variables that are given in period 1, and rewriting, we obtain the simplified fiscal rules for each member country of the union:

$$
\begin{aligned}
& g_{1}=k_{1}-\lambda y_{1} \\
& g_{2}=k_{2}-\lambda y_{2}
\end{aligned}
$$

Notice that if $\left(d_{i,-1}-d_{i}^{o}\right)>0$, then $k_{i}<0$, indicating a country with a relatively high level of debt. And the opposite holds for $k_{i}>0$, indicating a country with a relatively low level of debt.

To solve the optimization problem, we will assume that fiscal authorities (FAs) will try to minimize their loss function constrained by the economic framework (given by the reduced form of the macroeconomic model, equations (5) to (8)), and the explicit fiscal rule (equations (11) and (12)). Their goals will be to minimize output changes, $y_{\mathrm{i}}$, with stabilization purposes, and to minimize public deficit changes, $g_{i}$, in order to guarantee fiscal discipline.

In this framework, among the set of FAs decisions, we will focus on the individual management of fiscal policy, and on the case of a coordinated decision. In both cases, we will allow for the use of a fiscal rule in both countries. That optimization problem could describe a macroeconomic scenario similar the current situation of European Union fiscal governance, since the European Commission has recently enforced fiscal policy coordination and the use of numerical fiscal rules.

Solving the optimization problem, we will obtain the optimal (fiscal) policy, i.e., the optimal level of public deficit compatible with the stabilization goal (see Appendix for details). The optimization problem of country 1 (symmetric for country 2) when the FA plays individually, and in both countries a fiscal rule is used, is the following:

$$
\begin{aligned}
& \min _{g_{1}} \ell_{1}=y_{1}^{2}+\sigma g_{1}^{2} \\
& \text { s.t. (5) and (11) }
\end{aligned}
$$

And the solution, symmetric for $g_{2}$, is the following (see Appendix for details):

$$
g_{1}^{N, R}=-G_{1}^{N, R} v_{1} \pm G_{2}^{N, R} v_{2}
$$

The problem of coordinated decision of FAs using fiscal rule in both countries is as follows:

$$
\begin{aligned}
& \min _{g_{1}, g_{2}} L=\left[\frac{1}{2} \ell_{1}+\frac{1}{2} \ell_{2}\right] \\
& \text { s.t. (5), (6), (11) and (12) }
\end{aligned}
$$

where $\ell_{i}=y_{i}^{2}+\sigma g_{i}^{2} \quad i=1,2$ is the loss function of the FAs.

And the solution, symmetric for $g_{2}$, is the following (see Appendix for details):

$$
g_{1}^{C, R}=-G_{1}^{C, R} v_{1} \pm G_{2}^{C, R} v_{2}
$$




\subsection{The main results.}

To illustrate the current situation faced by the Eurozone countries, in the empirical application we have computed the values for the case of a common demand contractive shock, leading to contractive effects on output and prices, and provoking a rise on unemployment figures.

For doing that, we have adopted the following assumptions. The shocks suffered by the countries have been normalized to 1 , so they are perfectly symmetric in size, although the shocks may differ in their sign, being perfectly asymmetric in their effects. Next, we will give numerical values to the parameters of the equations describing the model features (See Diaz-Roldán (2017) for details).

(1) In the monetary rule: we will assign a relatively high value to the weight of the inflation goal, to characterize a more conservative central banker.

(2) In the fiscal rule, we will describe a "disciplined" scenario in which there is a greater concern about deviations of debt and accumulated deficit than about deviations in production, aimed to fulfil fiscal consolidation supranational requirements as can be observed in the Eurozone.

(3) In the loss function we would assume that fiscal authorities could be more concerned about fiscal discipline or, on the contrary, they could be more concerned about output growth, to characterize a more austere or less austere national fiscal authority.

After solving the optimization problems for the cooperative and the noncooperative solution of the fiscal authorities, we obtain the optimal solution for the budget deficits, and we are also able to calculate the corresponding values of output and inflation.

Additionally, we calculate the percentage of change of the unemployment rate $u$, when none FPSS is applied; and we calculate also the percentage of change of the unemployment rate $\mathcal{u}_{\mathrm{F}}$, when the fiscal authority applies any kind of FPSS (changes on contributions paid by employees, social security contributions by employers, payroll taxes, or indirect taxes). The numerical results for unemployment are reported in Table 1. Given the variables of the model are defined as logarithmic deviations from their equilibrium levels, and the values of the shocks have been normalized to 1 , the figures of the tables should be interpreted as deviation points from the equilibrium level. To the extent that our variable of interest is unemployment, figures on table 1 can be interpreted as the increase $(+)$ or decrease $(-)$ of the deviation of the actual unemployment rate from the NAIRU.

According to that, we will obtain different macroeconomic results depending on: (i) the degree of austerity of fiscal authorities' attitude, (ii) the initial level of government debt of countries; (iii) and the way in which fiscal authorities solve their optimization problem: in a cooperative or in an individual manner.

In Table 1 we can see the deviations of total unemployment using or not FPSS, under different macroeconomic scenarios. As have been explained above, the scenarios differ depending on the fiscal authorities' decision (cooperative of no cooperative), their preferences (austere or no austere), and the initial level of government debt. 
As can be seen, the best result (the biggest decrease of the deviation) is obtained when fiscal authorities act in a cooperative manner, have no austere preferences, apply FPSS, and both countries show low debt figures.

On the contrary, the worst result is produced when countries show high debt figures and the fiscal authorities cooperate. In the face of high debt levels, the no cooperative decision, joint with no austere preferences, proves to be the best.

Table 1

Total unemployment and GDP growth

\begin{tabular}{|c|c|c|}
\hline \multicolumn{3}{|c|}{ Cooperative solution } \\
\hline \multirow{4}{*}{ austere } & high debt & low debt \\
\hline & $\boldsymbol{u}=7.18$ & $\boldsymbol{u}=-8.64$ \\
\hline & $\boldsymbol{u}_{\boldsymbol{F}}=9.15$ & $\boldsymbol{u}_{F}=-16.09$ \\
\hline & $y=5.6$ & $y=5.18$ \\
\hline \multirow{3}{*}{$\begin{array}{c}\text { no } \\
\text { austere }\end{array}$} & $\boldsymbol{u}=11.74$ & $\boldsymbol{u}=-7.16$ \\
\hline & $\boldsymbol{u}_{F}=14.49$ & $\boldsymbol{u}_{\boldsymbol{F}}=-29.76$ \\
\hline & $y=10.04$ & $y=9.27$ \\
\hline \multicolumn{3}{|c|}{ Non cooperative solution } \\
\hline \multirow{4}{*}{ austere } & high debt & low debt \\
\hline & $\boldsymbol{u}=-2.73$ & $\boldsymbol{u}=3.00$ \\
\hline & $\boldsymbol{u}_{F}=-7.37$ & $\boldsymbol{u}_{F}=6.04$ \\
\hline & $y=-7.54$ & $y=6.96$ \\
\hline \multirow{3}{*}{$\begin{array}{c}\text { no } \\
\text { austere }\end{array}$} & $\boldsymbol{u}=-4.04$ & $\boldsymbol{u}=5.88$ \\
\hline & $\boldsymbol{u}_{F}=-12.09$ & $\boldsymbol{u}_{F}=11.76$ \\
\hline & $y=-13.64$ & $y=12.59$ \\
\hline
\end{tabular}

Source: Own elaboration based on the model by Díaz-Roldán (2017) and the described scenario. Notes: $\boldsymbol{u}=$ total unemployment without using fiscal policy by the supply-side $\boldsymbol{u}_{F}=$ total unemployment after applying any fiscal policy by the supply-side

\subsection{The empirical application to the Eurozone}

Since we are interested on the collective affected by youth unemployment in the Eurozone, we will show the changes of the figures reported in Table 1 if we apply those qualitative results to Eurozone members. As we mentioned in the Introduction section, in the Eurozone, the financial crisis effects have been hit countries in a different manner. For that reason, we will differentiate three sets of countries: the core, the peripheral and the Eastern countries ${ }^{1}$. Those groups have not shown the same macroeconomic trend after the recent crisis, especially if we look at their rates of growth in Table 2.

\footnotetext{
${ }^{1}$ Eurozone countries: Austria, Belgium, Cyprus, Estonia, Finland, France, Germany, Greece, Ireland, Italy, Lithuania, Luxembourg, Malta, the Netherlands, Portugal, Slovakia, Slovenia and Spain.

CORE countries: Belgium, France, Germany, Luxembourg, the Netherlands.

PIIGS countries: Portugal, Ireland, Italy, Greece, Spain.

CEE countries belonging to Eurozone: Estonia, Latvia, Lithuania, Slovak Republic, Slovenia.
} 
In Table 2 we can see the real GDP growth rate. The countries grouped as PIIGS, show figures three times higher than the CORE countries ten years after the crisis.

Table 2: Real GDP growth rate, \% change on previous year.

\begin{tabular}{|c|c|c|c|c|}
\hline & Eurozone & CORE & PIIGS & CEE \\
\hline 2007 & 3.10 & 4.26 & 3.28 & 9.30 \\
\hline 2017 & 2.40 & 2.26 & 3.20 & 4.34 \\
\hline
\end{tabular}

Source: Eurostat

As showed in Table 3, in 2017, the youth unemployment in PIIGS countries, doubles the figure of youth unemployment in the CORE countries.

Table 3: Percentage of active population (seasonally adjusted data) of youth unemployment (less than 25 years).

\begin{tabular}{|c|c|c|c|c|}
\hline & Eurozone & CORE & PIIGS & CEE \\
\hline 2007 & 15.50 & 15.00 & 18.40 & 12.00 \\
\hline 2017 & 18.33 & 14.54 & 31.10 & 14.51 \\
\hline
\end{tabular}

Source: Eurostat

Taking in account data on Tables 2 and 3, we have computed the percentage of change of the youth unemployment rate when none FPSS is applied; and the percentage of change of the youth unemployment rate, when the fiscal authority applies any kind of FPSS.

The obtained results for total unemployment and GDP growth, showed in Table 1, hold when looking at total youth unemployment of the Eurozone (Table 4).

Table 4

Youth unemployment, and GDP growth. Total Eurozone (19) countries

\begin{tabular}{|c|c|c|c|c|}
\hline \multicolumn{5}{|c|}{ Cooperative solution } \\
\hline \multirow{5}{*}{ austere } & \multicolumn{2}{|c|}{ high debt } & \multicolumn{2}{|c|}{ low debt } \\
\hline & 2007 & 2017 & 2007 & 2017 \\
\hline & $\boldsymbol{u}=1.11$ & $\boldsymbol{u}=1.32$ & $\boldsymbol{u}=-1.34$ & $\boldsymbol{u}=-1.58$ \\
\hline & $\boldsymbol{u}_{\boldsymbol{F}}=1.42$ & $\boldsymbol{u}_{F}=1.68$ & $\boldsymbol{u}_{F}=-2.49$ & $\boldsymbol{u}_{F}=-2.95$ \\
\hline & $y=0.17$ & $y=0.13$ & $y=0.16$ & $y=0.12$ \\
\hline \multirow{3}{*}{$\begin{array}{c}\text { no } \\
\text { austere }\end{array}$} & $\boldsymbol{u}=1.82$ & $\boldsymbol{u}=2.15$ & $\boldsymbol{u}=-1.11$ & $\boldsymbol{u}=-1.31$ \\
\hline & $\boldsymbol{u}_{\boldsymbol{F}}=2.25$ & $\boldsymbol{u}_{F}=2.66$ & $\boldsymbol{u}_{F}=-4.61$ & $\boldsymbol{u}_{F}=-5.46$ \\
\hline & $y=0.31$ & $y=0.24$ & $y=0.29$ & $y=0.22$ \\
\hline \multicolumn{5}{|c|}{ Non cooperative solution } \\
\hline \multirow{5}{*}{ austere } & \multicolumn{2}{|c|}{ high debt } & \multicolumn{2}{|c|}{ low debt } \\
\hline & 2007 & 2017 & 2007 & 2017 \\
\hline & $\boldsymbol{u}=-0.42$ & $\boldsymbol{u}=-0.50$ & $\boldsymbol{u}=0.47$ & $\boldsymbol{u}=-0.74$ \\
\hline & $\boldsymbol{u}_{F}=-1.14$ & $\boldsymbol{u}_{F}=-1.35$ & $\boldsymbol{u}_{\boldsymbol{F}}=0.94$ & $\boldsymbol{u}_{\boldsymbol{F}}=-2.22$ \\
\hline & $y=-0.23$ & $y=-0.18$ & $y=0.22$ & $y=0.17$ \\
\hline \multirow{3}{*}{$\begin{array}{c}\text { no } \\
\text { austere }\end{array}$} & $\boldsymbol{u}=-0.63$ & $\boldsymbol{u}=-0.74$ & $\boldsymbol{u}=0.91$ & $\boldsymbol{u}=1.08$ \\
\hline & $\boldsymbol{u}_{\boldsymbol{F}}=-1.87$ & $\boldsymbol{u}_{F}=-2.22$ & $\boldsymbol{u}_{F}=1.82$ & $\boldsymbol{u}_{F}=2.16$ \\
\hline & $y=-0.42$ & $y=-0.33$ & $\boldsymbol{y}=0.39$ & $\boldsymbol{y}=0.30$ \\
\hline
\end{tabular}

Source: Own elaboration based on Table 1 and data obtained from Eurostat.

Notes: $\boldsymbol{u}=$ youth unemployment without using fiscal policy by the supply-side $\boldsymbol{u}_{\boldsymbol{F}}=$ youth unemployment after applying any fiscal policy by the supply-side 
In Table 5 we can see the average of government debt. The countries grouped as PIIGS double debt figures in ten years and show figures three times higher than the CORE countries, ten years after the crisis.

Table 5: Gross government debt, average, percentage GDP.

\begin{tabular}{|c|c|c|c|c|}
\hline & Eurozone & CORE & PIIGS & CEE \\
\hline 2007 & 65.00 & 53.12 & 66.16 & 16.10 \\
\hline 2017 & 86.70 & 68.78 & 120.45 & 42.66 \\
\hline
\end{tabular}

Source: Eurostat

Having debt figures into account we could conclude that, in terms of our model, CORE and CEE countries are "low debt" countries, and PIIGS are "high debt" countries, since their debt figures are always under or below the Eurozone average, respectively. Having this into account we have split the Eurozone in three sets of countries (the CORE, the PIIGS and the CEE countries), as we can see in Tables 6 to 8.

Table 6

Youth unemployment CORE Eurozone countries

\begin{tabular}{|c|c|c|c|c|}
\hline \multicolumn{5}{|c|}{ Cooperative solution } \\
\hline \multirow{5}{*}{ austere } & \multicolumn{2}{|c|}{ high debt } & \multicolumn{2}{|c|}{ low debt } \\
\hline & 2007 & 2017 & 2007 & 2017 \\
\hline & $\boldsymbol{u}=1.08$ & $\boldsymbol{u}=1.04$ & $\boldsymbol{u}=-1.30$ & $\boldsymbol{u}=-1.26$ \\
\hline & $\boldsymbol{u}_{F}=1.37$ & $\boldsymbol{u}_{F}=1.33$ & $\boldsymbol{u}_{F}=-2.41$ & $\boldsymbol{u}_{F}=-2.34$ \\
\hline & $y=0.24$ & $y=0.13$ & $y=0.22$ & $y=0.12$ \\
\hline \multirow{3}{*}{$\begin{array}{c}\text { no } \\
\text { austere }\end{array}$} & $\boldsymbol{u}=1.76$ & $\boldsymbol{u}=1.71$ & $\boldsymbol{u}=-1.07$ & $\boldsymbol{u}=-1.04$ \\
\hline & $\boldsymbol{u}_{\boldsymbol{F}}=2.17$ & $\boldsymbol{u}_{F}=2.11$ & $\boldsymbol{u}_{F}=-4.46$ & $\boldsymbol{u}_{F}=-4.33$ \\
\hline & $y=0.43$ & $y=0.23$ & $y=0.39$ & $y=0.21$ \\
\hline \multicolumn{5}{|c|}{ Non cooperative solution } \\
\hline \multirow{5}{*}{ austere } & \multicolumn{2}{|c|}{ high debt } & \multicolumn{2}{|c|}{ low debt } \\
\hline & 2007 & 2017 & 2007 & 2017 \\
\hline & $\boldsymbol{u}=-0.41$ & $\boldsymbol{u}=-0.40$ & $\boldsymbol{u}=0.45$ & $\boldsymbol{u}=0.44$ \\
\hline & $\boldsymbol{u}_{F}=-1.11$ & $\boldsymbol{u}_{F}=-1.07$ & $\boldsymbol{u}_{F}=0.91$ & $\boldsymbol{u}_{\boldsymbol{F}}=0.88$ \\
\hline & $y=-0.32$ & $y=-0.17$ & $y=0.30$ & $y=0.16$ \\
\hline \multirow{3}{*}{$\begin{array}{c}\text { no } \\
\text { austere }\end{array}$} & $\boldsymbol{u}=-0.61$ & $\boldsymbol{u}=-0.59$ & $\boldsymbol{u}=0.88$ & $\boldsymbol{u}=0.85$ \\
\hline & $\boldsymbol{u}_{F}=-1.81$ & $\boldsymbol{u}_{F}=-1.76$ & $\boldsymbol{u}_{F}=1.76$ & $\boldsymbol{u}_{\boldsymbol{F}}=1.71$ \\
\hline & $\boldsymbol{y}=-0.58$ & $y=-0.31$ & $y=0.54$ & $y=0.28$ \\
\hline
\end{tabular}

Source: Own elaboration based on Table 1 and data obtained from Eurostat. Notes: $\boldsymbol{u}=$ youth unemployment without using fiscal policy by the supply-side $\boldsymbol{u}_{\boldsymbol{F}}=$ youth unemployment after applying any fiscal policy by the supply-side 
Table 7

Youth unemployment PIIGS Eurozone countries

\begin{tabular}{|c|c|c|c|c|}
\hline \multicolumn{5}{|c|}{ Cooperative solution } \\
\hline \multirow{5}{*}{ austere } & \multicolumn{2}{|c|}{ high debt } & \multicolumn{2}{|c|}{ low debt } \\
\hline & 2007 & 2017 & 2007 & 2017 \\
\hline & $\boldsymbol{u}=1.32$ & $\boldsymbol{u}=2.23$ & $\boldsymbol{u}=-1.59$ & $\boldsymbol{u}=-2.69$ \\
\hline & $\boldsymbol{u}_{\boldsymbol{F}}=1.68$ & $\boldsymbol{u}_{\boldsymbol{F}}=2.85$ & $\boldsymbol{u}_{F}=-2.96$ & $\boldsymbol{u}_{F}=-5.00$ \\
\hline & $y=0.18$ & $y=0.18$ & $y=0.17$ & $y=0.17$ \\
\hline \multirow{3}{*}{$\begin{array}{c}\text { no } \\
\text { austere }\end{array}$} & $u=2.16$ & $u=3.65$ & $\boldsymbol{u}=-1.32$ & $\boldsymbol{u}=-2.23$ \\
\hline & $\boldsymbol{u}_{\boldsymbol{F}}=2.67$ & $\boldsymbol{u}_{\boldsymbol{F}}=4.51$ & $\boldsymbol{u}_{\boldsymbol{F}}=-5.48$ & $\boldsymbol{u}_{\boldsymbol{F}}=-9.26$ \\
\hline & $y=0.33$ & $y=0.32$ & $y=0.30$ & $y=0.30$ \\
\hline \multicolumn{5}{|c|}{ Non cooperative solution } \\
\hline \multirow{5}{*}{ austere } & \multicolumn{2}{|c|}{ high debt } & \multicolumn{2}{|c|}{ low debt } \\
\hline & 2007 & 2017 & 2007 & 2017 \\
\hline & $\boldsymbol{u}=-0.50$ & $\boldsymbol{u}=-0.85$ & $\boldsymbol{u}=0.55$ & $\boldsymbol{u}=0.93$ \\
\hline & $\boldsymbol{u}_{F}=-1.36$ & $\boldsymbol{u}_{\boldsymbol{F}}=-2.29$ & $\boldsymbol{u}_{F}=1.11$ & $\boldsymbol{u}_{\boldsymbol{F}}=1.88$ \\
\hline & $y=-0.25$ & $y=-0.24$ & $y=0.23$ & $y=0.22$ \\
\hline \multirow{3}{*}{$\begin{array}{c}\text { no } \\
\text { austere }\end{array}$} & $u=-0.74$ & $u=-1.26$ & $\boldsymbol{u}=1.08$ & $\boldsymbol{u}=1.83$ \\
\hline & $u_{F}=-2.22$ & $u_{F}=-3.76$ & $\boldsymbol{u}_{\boldsymbol{F}}=2.16$ & $u_{F}=3.66$ \\
\hline & $y=-0.45$ & $y=-0.44$ & $y=0.41$ & $y=0.40$ \\
\hline
\end{tabular}

Source: Own elaboration based on Table 1 and data obtained from Eurostat Notes: $\boldsymbol{u}=$ youth unemployment without using fiscal policy by the supply-side $\boldsymbol{u}_{\boldsymbol{F}}=$ youth unemployment after applying any fiscal policy by the supply-side

Table 8

Youth unemployment CEE Eurozone countries

\begin{tabular}{|c|c|c|c|c|}
\hline \multicolumn{5}{|c|}{ Cooperative solution } \\
\hline \multirow{5}{*}{ austere } & \multicolumn{2}{|c|}{ high debt } & \multicolumn{2}{|c|}{ low debt } \\
\hline & 2007 & 2017 & 2007 & 2017 \\
\hline & $\boldsymbol{u}=1.08$ & $\boldsymbol{u}=1.04$ & $\boldsymbol{u}=-1.30$ & $\boldsymbol{u}=-1.25$ \\
\hline & $\boldsymbol{u}_{\boldsymbol{F}}=1.37$ & $\boldsymbol{u}_{\boldsymbol{F}}=1.33$ & $\boldsymbol{u}_{F}=-2.41$ & $\boldsymbol{u}_{F}=-2.33$ \\
\hline & $y=0.52$ & $y=0.24$ & $y=0.48$ & $y=0.22$ \\
\hline \multirow{3}{*}{$\begin{array}{c}\text { no } \\
\text { austere }\end{array}$} & $u=1.76$ & $\boldsymbol{u}=1.70$ & $\boldsymbol{u}=-1.07$ & $\boldsymbol{u}=-1.04$ \\
\hline & $\boldsymbol{u}_{F}=2.17$ & $\boldsymbol{u}_{F}=2.10$ & $u_{F}=-4.45$ & $u_{F}=-4.32$ \\
\hline & $y=0.93$ & $y=0.44$ & $\boldsymbol{y}=0.86$ & $y=0.40$ \\
\hline \multicolumn{5}{|c|}{ Non cooperative solution } \\
\hline \multirow{5}{*}{ austere } & \multicolumn{2}{|c|}{ high debt } & \multicolumn{2}{|c|}{ low debt } \\
\hline & 2007 & 2017 & 2007 & 2017 \\
\hline & $\boldsymbol{u}=-0.41$ & $\boldsymbol{u}=-0.40$ & $\boldsymbol{u}=0.45$ & $\boldsymbol{u}=0.44$ \\
\hline & $\boldsymbol{u}_{F}=-1.11$ & $\boldsymbol{u}_{F}=-1.07$ & $\boldsymbol{u}_{F}=0.91$ & $\boldsymbol{u}_{\boldsymbol{F}}=0.88$ \\
\hline & $y=-0.70$ & $y=-0.33$ & $y=0.65$ & $y=0.30$ \\
\hline \multirow{3}{*}{$\begin{array}{c}\text { no } \\
\text { austere }\end{array}$} & $\boldsymbol{u}=-0.61$ & $\boldsymbol{u}=-0.59$ & $\boldsymbol{u}=0.88$ & $\boldsymbol{u}=0.85$ \\
\hline & $\boldsymbol{u}_{F}=-1.81$ & $\boldsymbol{u}_{F}=-1.75$ & $\boldsymbol{u}_{\boldsymbol{F}}=1.76$ & $\boldsymbol{u}_{F}=1.71$ \\
\hline & $y=-1.27$ & $y=-0.59$ & $y=1.17$ & $y=0.55$ \\
\hline
\end{tabular}

Source: Own elaboration based on Table 1 and data obtained from Eurostat.

Notes: $\boldsymbol{u}=$ youth unemployment without using fiscal policy by the supply-side $\boldsymbol{u}_{\boldsymbol{F}}=$ youth unemployment after applying any fiscal policy by the supply-side 
According to our model, when looking at Tables 6 to 8 , we can see the results of stabilization fiscal policies by the supply-side, in terms of output and young unemployment before the crisis, 2007, and ten years later, 2017. Those results would indicate that:

- For the CORE and the CEE countries, the best solution for:

o fighting youth unemployment would be given by the cooperation among their fiscal authorities (when having decisions on the optimal level of government deficit), act in a no austere manner (showing a growth promoting preferences) and use any kind of fiscal policy by the supply side.

○ promoting output growth, would be given by no cooperation and no austerity.

- For the PIIGS countries, the best solution would be:

o for fighting youth unemployment: no cooperation among fiscal authorities (i.e., not to implement the same objective for government deficit when managing fiscal policy at country level); act in a no austere manner and use any kind of fiscal policy by the supply side.

- For promoting output growth: cooperation and no austerity.

Notice that under our model assumptions (conservative central banker, and the use of a disciplined fiscal rule aimed to achieve fiscal consolidation), fiscal authorities should be no austere for achieving better results when fighting youth unemployment, and also for promoting economic growth. In other words, when optimizing their loss function, they should give more weight to the output stabilization goal that to the government deficit reduction.

\section{Concluding remarks}

In this paper, we have analysed the effects of stabilization policies on youth unemployment, using government deficit besides the use of fiscal policy by the supply side; aimed to characterize the economic framework conditions under which fiscal policy could reduce youth unemployment in a monetary union.

To that aim, we have considered an economic framework featuring the use of monetary and fiscal rules within a monetary union. In this scenario, that should be representative of the Eurozone, we have analysed the effects of stabilization policies when dealing with a financial crisis having contractive effects on output. We have payed special attention to the conservativeness of the central bank, the degree of austerity of the fiscal authorities and the initial level of public debt. Those characteristics prove to be crucial for the sustainability of economic policies packages based on fiscal consolidation and the use of fiscal policy instruments by the supply side.

But in the Eurozone, the financial crisis effects have been hit countries in a different manner. Certain groups of the periphery have showed more vulnerable, producing alarming figures on output decreases and unemployment increases, particularly 
those of youth unemployment. This compromise the inter-generational aspects of sustainable growth and development. For that reason, in our analysis, we have differentiated monetary union's member countries according with their macroeconomic performance.

According to our results, the CORE and the CEE countries, when fighting youth unemployment should coordinate their fiscal authorities' decisions, act in a no austere manner and they should use any kind of fiscal policy by the supply side. On the contrary, the PIIGS countries, should manage their fiscal policies in an individual way, act in a no austere manner and they also should use any kind of fiscal policy by the supply side. Regarding output growth, the CORE and the CEE countries should no coordinate their fiscal police, and PIIGS countries should coordinate; but the three set of countries should apply no austere policies.

\section{Appendix}

\section{The macroeconomic model}

Demand side

$$
\begin{aligned}
& y_{1}=-\alpha r+\beta\left(p_{2}-p_{1}\right)+\gamma y_{2}+g_{1} \\
& y_{2}=-\alpha r+\beta\left(p_{1}-p_{2}\right)+\gamma y_{1}+g_{2} \\
& r=\mu\left[\frac{1}{2}\left(\Delta p_{1}+\Delta p_{2}\right)-\Delta p^{o}\right]
\end{aligned}
$$

From (1.A) to (3.A) we obtain the aggregate demand for each country

\section{Supply side}

$$
\begin{aligned}
& y_{1}=-a \Delta p_{1} \pm b \Delta p_{2} \pm c y_{2}+h g_{1}+v_{1} \\
& y_{2}=-a \Delta p_{2} \pm b \Delta p_{1} \pm c y_{1}+h g_{2}+v_{2}
\end{aligned}
$$

$$
\begin{aligned}
& \Delta w_{1}=\Delta p_{1 c}^{E}-\varphi u_{1}+\phi \Delta \operatorname{prod}_{1}+z_{1}^{w} \\
& \Delta p_{1}=\Delta w_{1}-\phi \Delta \operatorname{prod}_{1}+z_{1}^{p} \\
& n_{1}=y_{1}-\operatorname{prod}_{1} \\
& p_{1 c}^{E}=p_{1 c,-1} \\
& p_{1 c}=\eta p_{1}+(1-\eta) p_{2} \\
& u_{1} \equiv l_{1}-n_{1}
\end{aligned}
$$

Where $z^{\mathrm{w}}$ captures the exogenous factors affecting wages determination, including taxes affecting labor market, such as contributions paid by employees, payroll taxes and indirect taxes. And $z^{\mathrm{p}}$ captures exogenous factors that affect pricing, including social security contributions by employers. 
From (4.A) to (9.A) we obtain the aggregate supply for each country

$$
\begin{aligned}
& y_{1}=t \Delta p_{1}-s_{1} \\
& y_{2}=t \Delta p_{2}-s_{2}
\end{aligned}
$$

The "beggar-thy-neighbour" effect prevails when policy-makers are particularly concerned by inflation targeting instead by output stabilization (the coefficient $\mu$, in the monetary rule equation (3.A) - is high enough when there is also an explicit output stabilization goal, or simply when inflation targeting is the unique objective as in our monetary rule).

\section{Aggregate demand coefficients}

$$
\begin{aligned}
& a=\frac{\alpha \mu+2 \beta}{2 d i v} \quad b=\frac{\alpha \mu-2 \beta}{2 d i v} \quad c=\frac{\alpha-2 \gamma}{2 d i v} \text { and } \operatorname{div}=\frac{2+\alpha}{2}, h=\frac{1}{d i v} \\
& v_{i}=-\frac{\alpha}{d i v} r_{A}+\frac{\alpha \mu}{d i v} \Delta p^{o}+\frac{\beta}{d i v} p_{2,-1}-\frac{\beta}{d i v} p_{1,-1}
\end{aligned}
$$

\section{Aggregate supply coefficients}

$$
\begin{aligned}
& t=\frac{1}{\varphi} \\
& s_{i}=-\frac{1}{\varphi} \Delta p_{c,-1}+l+\operatorname{prod}-\frac{1}{\varphi}\left(z^{p}+z^{w}\right)
\end{aligned}
$$

\section{Reduced form}

$$
\begin{aligned}
& \text { den }=(c t+b)^{2}-(a+t)^{2}<0 \\
& \mathrm{~A}=-\frac{(a+t)}{d e n} t>0, \mathrm{~B}=\frac{(b+c t)}{d e n} t>0, \mathrm{C}=\frac{(a-b c) t+a^{2}-b^{2}}{d e n}>0, \mathrm{D}=\frac{(b-a c)}{d e n} t>0 \\
& \mathrm{~A}^{\prime}=-\frac{(a+t)}{d e n}>0, \mathrm{~B}^{\prime}=\frac{(b+c t)}{d e n}>0, \mathrm{C}^{\prime}=\frac{(b-c t) c-(a+t)}{d e n}>0, \mathrm{D}^{\prime}=\frac{(b-a c)}{d e n}>0
\end{aligned}
$$

Solving (1) to (4), we obtain the reduced forms:

$$
\begin{gathered}
y_{1}=\mathrm{A} h g_{1}+\mathrm{A} v_{1} \pm \mathrm{B} h g_{2} \pm \mathrm{B} v_{2}-\mathrm{C} s_{1}-\mathrm{D} s_{2} \\
y_{2}=\mathrm{A} h g_{2}+\mathrm{A} v_{2} \pm \mathrm{B} h g_{1} \pm \mathrm{B} v_{1}-\mathrm{C} s_{2}-\mathrm{D} s_{1} \\
\Delta p_{1}=\mathrm{A}^{\prime} h g_{1}+\mathrm{A}^{\prime} v_{1}+\mathrm{B}{ }^{\prime} h g_{2}+\mathrm{B} v_{2}+\mathrm{C}^{\prime} s_{1}+\mathrm{D}^{\prime} s_{2} \\
\Delta p_{2}=\mathrm{A}^{\prime} h g_{2}+\mathrm{A}^{\prime} v_{2}+\mathrm{B}{ }^{\prime} h g_{1}+\mathrm{B}^{\prime} v_{1}+\mathrm{C}^{\prime} s_{2}+\mathrm{D}^{\prime} s_{1}
\end{gathered}
$$

When the "beggar-thy-neighbour" effect prevails (inflation targeting):

$$
\begin{gathered}
y_{1}=\mathrm{A} h g_{1}+\mathrm{A} v_{1}-\mathrm{B} h g_{2}-\mathrm{B} v_{2}-\mathrm{C} s_{1}-\mathrm{D} s_{2} \\
y_{2}=\mathrm{A} h g_{2}+\mathrm{A} v_{2}-\mathrm{B} h g_{1}-\mathrm{B} v_{1}-\mathrm{C} s_{2}-\mathrm{D} s_{1} \\
\Delta p_{1}=\mathrm{A}^{\prime} h g_{1}+\mathrm{A}^{\prime} v_{1}+\mathrm{B}{ }^{\prime} h g_{2}+\mathrm{B} v_{2}+\mathrm{C}^{\prime} s_{1}+\mathrm{D}^{\prime} s_{2} \\
\Delta p_{2}=\mathrm{A}^{\prime} h g_{2}+\mathrm{A}^{\prime} v_{2}+\mathrm{B}{ }^{\prime} h g_{1}+\mathrm{B} v_{1}+\mathrm{C}^{\prime} s_{2}+\mathrm{D}^{\prime} s_{1}
\end{gathered}
$$

\section{Optimization problem}

Independent decision and fiscal rule in both countries

$$
\begin{aligned}
& \min _{g_{1}} \ell_{1}=y_{1}^{2}+\sigma g_{1}^{2} \\
& \text { s.t. (5) and (11) }
\end{aligned}
$$

Reaction functions:

$$
\begin{aligned}
& g_{1}^{N, R}=g_{1}\left(g_{2}\right)=q_{1}^{N, R} g_{2}+q_{2}^{N, R} v_{2}-q_{3}^{N, R} v_{1}-q_{4}^{N, R} \\
& q_{1}^{N, R}, q_{2}^{N, R}, q_{3}^{N, R}, q_{4}^{N, R}>0
\end{aligned}
$$


where

$$
\begin{aligned}
& \left|q_{4}^{N, R}\right|>0 \text { if } k_{1}>0 \\
& \left|q_{4}^{N, R}\right|<0 \quad \text { if } k_{1}<0 \\
& q_{1}^{N, R}=\frac{B}{A}, q_{2}^{N, R}=\frac{B}{A h}, q_{3}^{N, R}=\frac{1}{h}, q_{4}^{N, R}=\frac{k_{1} \lambda \sigma}{A h\left(1+\lambda_{2} \sigma\right)}
\end{aligned}
$$

Solving:

$$
\begin{aligned}
G_{1}^{N, R} & =-\frac{1}{h}-\frac{k_{1} \sigma \lambda}{h\left(1+\sigma \lambda^{2}\right)(A-B)}=\frac{(B-A)\left(1+\sigma \lambda^{2}\right)-k_{1} \sigma \lambda}{h\left(1+\sigma \lambda^{2}\right)(A-B)} \\
G_{2}^{N, R} & =0-\frac{k_{1} \sigma \lambda}{h\left(1+\sigma \lambda^{2}\right)(A-B)}
\end{aligned}
$$

Solution (symmetric for $g_{2}$ ): $\quad g_{1}^{N, R}=-G_{1}^{N, R} v_{1} \pm G_{2}^{N, R} v_{2}$

$\underline{\text { Coordinated decision and fiscal rule in both countries }}$

$$
\begin{aligned}
& \min _{g_{1}, g_{2}} L=\left[\frac{1}{2} \ell_{1}+\frac{1}{2} \ell_{2}\right] \\
& \text { s.t. (5), (6), (11) and (12) }
\end{aligned}
$$

Reaction functions:

$$
\begin{aligned}
& g_{1}^{C, R}=g_{1}\left(g_{2}\right)=q_{1}^{C, R} g_{2}+q_{2}^{C, R} v_{2}-q_{3}^{C, R} v_{1}-q_{4}^{C, R} \\
& q_{1}^{C, R}, q_{2}^{C, R}, q_{3}^{C, R}, q_{4}^{C, R}>0, q_{4}^{C, R} \\
& \text { where } \\
& \left|q_{4}^{C, R}\right|>0 \text { if }\left(A k_{1}-B k_{2}\right)<0 \\
& \left|q_{4}^{C, R}\right|<0 \text { if }\left(A k_{1}-B k_{2}\right)>0 \\
& q_{1}^{C, R}=\frac{2 A B}{\left(A^{2}+B^{2}\right)}, q_{2}^{C, R}=\frac{2 A B}{\left(A^{2}+B^{2}\right) h}, q_{3}^{C, R}=\frac{1}{h} \\
& q_{4}^{C, R}=\frac{\left(A k_{1}-B k_{2}\right) \lambda \sigma}{\left(A^{2}+B^{2}\right) h\left(1+\lambda^{2} \sigma\right)}
\end{aligned}
$$

Solving:

$$
\begin{aligned}
G_{1}^{C, R} & =-\frac{1}{h}-\frac{\left(A k_{1}-B k_{2}\right) \sigma_{1} \lambda}{h\left(1+\sigma_{1} \lambda^{2}\right)(A-B)^{2}}=-\frac{\left(1+\sigma \lambda^{2}\right)(A-B)^{2}+\left(A k_{1}-B k_{2}\right) \sigma_{1} \lambda}{h\left(1+\sigma_{1} \lambda^{2}\right)(A-B)^{2}} \\
G_{2}^{C, R} & =-\frac{\left(A k_{1}-B k_{2}\right) \sigma_{2} \lambda}{h\left(1+\sigma_{2} \lambda^{2}\right)(A-B)^{2}}
\end{aligned}
$$

Solution (symmetric for $g_{2}$ ): $\quad g_{1}^{C, R}=-G_{1}^{C, R} v_{1} \pm G_{2}^{C, R} v_{2}$ 


\section{Numerical values for the empirical exercise}

Parameters of the model

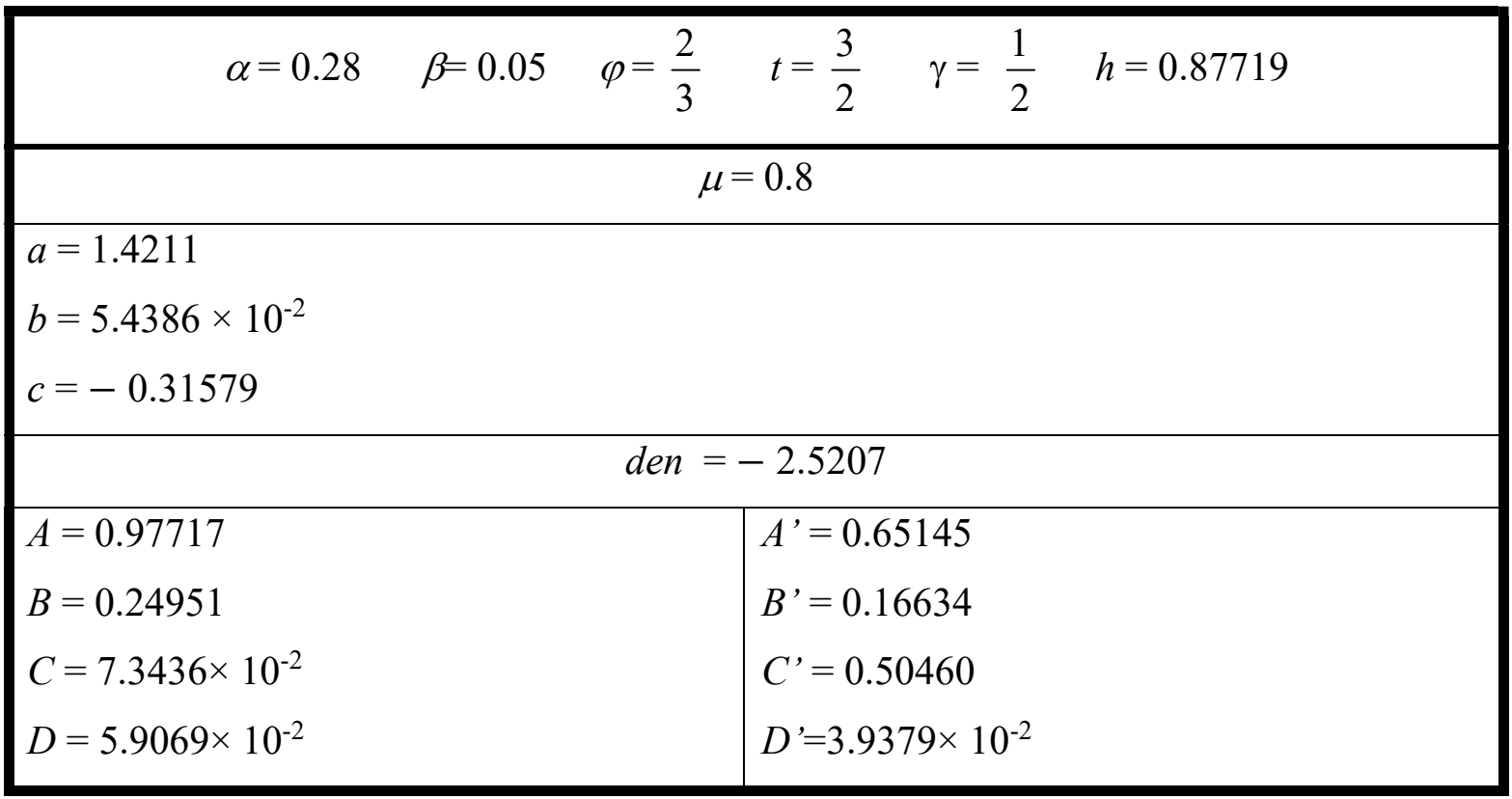

Parameters of the fiscal rule

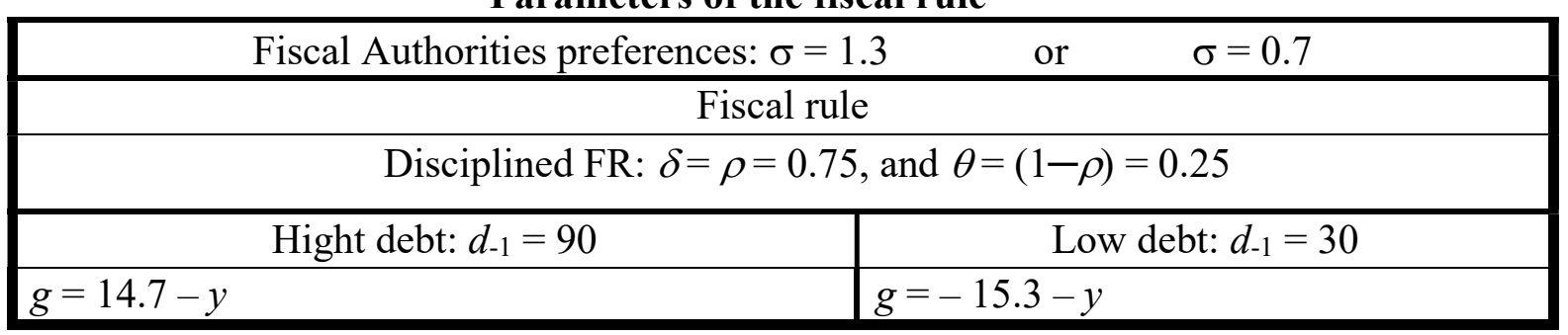

\section{Effects on unemployment rate}

From equations 6.A and 9.A we find that:

$l_{\mathrm{i}}+\operatorname{prod}_{\mathrm{i}}=u_{\mathrm{i}}+y_{\mathrm{i}}$

Substituting in $s_{\mathrm{i}}$, we obtain:

$s_{i}=-\frac{1}{\varphi} \Delta p_{c,-1}+u_{i}+y_{i}-\frac{1}{\varphi}\left(z^{p}+z^{w}\right)$

Assuming that $\Delta p_{c,-1}$ is equal to $\Delta p_{i}$ when none shocks occurs, we will calculate:

a. The value of $u_{\mathrm{i}}$ for $s_{\mathrm{i}}=0$, when $\left(z^{\mathrm{p}}+z^{\mathrm{w}}\right)=0$ (value of $u$ in Tables).

b. The value of $u_{\mathrm{i}}$ for $s_{\mathrm{i}}=0$, when $\left(z^{\mathrm{p}}+z^{\mathrm{w}}\right) \neq 0$, i.e., when union has any bargaining power (value of $u_{\mathrm{B}}$ in Table 1). We have asigned $\left(z^{\mathrm{p}}+z^{\mathrm{w}}\right)=0.5$ 


\section{References}

Ahlborn, M and Wortmann, M. (2017): "Output gap similarities in Europe: detecting country groups", Center for European Governance and Economic Development Research, Discussion Papers, N. 305, February 2017, Georg-August Universität Göttingen, Germany.

Ballabriga, F. and Martínez-Mongay, C. (2003). "Has EMU shifted monetary and fiscal policies?", in Buti, M. (ed.): Monetary and fiscal policies in EMU. Interactions and coordination, Cambridge University Press.

Bertola, G. (2017): "European unemployment revisited: Shocks, institutions, integration", Research in Economics 71(3), 588-612.

Blanchard, O.J. (2004): "Explaining European unemployment", NBER Reporter, Summer 2004.

Díaz-Roldán, C. (2017): "Fiscal Performance in Monetary Unions: How Much Austerity Should Be Allowed?", Panoeconomicus, 64 (1), 61-76.

http://www.doiserbia.nb.rs/img/doi/1452-595X/2017/1452-595X1600021D.pdf

Díaz-Roldán, C. (2018): "On the effectiveness of fiscal policies by the supply side in monetary unions", Universidad de Castilla-La Mancha, mimeo.

European Central Bank (2013): "The importance and effectiveness of national fiscal frameworks in the EU", Monthly Bulletin, February, 73-88.

European Commission (2008): Recommendation of the European Commission 2008/867 / EC, of October 3, 2008

European Commission (2017): Press release, 30 May 2017.

Gómez, S., Gómez, E., Bardí, C. and Barón, J. (2016): “El camino hacia el empleo juvenil" ("The road to yout employment"), Observatorio empresarial contra la pobreza, Fundación Tomillo y Fundación CODESPA.

Rozmahel, P., Grochová, L.I. and Liztman, M. (2014): "Evaluation of competitiveness in the European Union: alternative perspectives", Procedia Economics and Finance $12,575-581$. 